\title{
The Fragmentation of Entrepreneurial Function and the Role of External Control on Management Behavior
}

\author{
Pietro Gottardo, Anna Maria Moisello \\ Dipartimento di Ricerche Aziendali “Riccardo Argenziano”, Università degli Studi di Pavia, Pavia, Italy. \\ Email: amoisello@eco.unipv.it
}

Received September 25 ${ }^{\text {th }}$, 2011; revised October $28^{\text {th }}$, 2011; accepted November $11^{\text {th }}, 2011$.

\begin{abstract}
Starting from the interpretation of corporate governance as the outcome of the fragmentation of entrepreneurial power and the related agency problem, the paper stresses the strict relationship between management control and risk management. This issue implies the need of effective internal and external controls, i.e. board implementation and supervision of a consistent control function and auditing, but the market and public regulatory authorities give the most important external control system. The paper focuses next on the role of the Codes of Conduct, the critical aspects of their effectiveness and other key issues in the governance of corporations highlighted by the last financial and economic crisis.
\end{abstract}

Keywords: Entrepreneur, Corporate Governance, Managerial Behavior, Ownership Structure, Risk Management

\section{Introduction}

The entrepreneurial function consists of the necessary decisions for the firm to carry out production, organisation and financial processes, in order to achieve a wellbalanced economic development. These activities consist in the transformation of information and objectives which are the constraints of the decision-making process - in decisions, plans and programs put into explicit management operations by means of the work of organizational function. Therefore the core entrepreneurial activiity consists of a set of calculations carried out by the entrepreneur in order to take rational decisions and to accomplish the profitability opportunities that arise in various ways [1-5]. So we define "entrepreneurial computing activity" the set of quantitative determinations required to assess, in terms of efficiency, the possible alternative courses of action for achieving the objectives. These calculations, depending on the nature of the transformation involved in the decision, may be technical, economic and financial. The information, which constitutes the input of the entrepreneurial computing activity, relates to the internal variables of the firm, the conditions that characterize the supply and market and the institutional constraints that affect the economic operations of the unit. The production is developed in an environment characterized by constant technical, economic and social changes that must be kept constantly under control. The company achieves its goals in an efficient way when it gets the information necessary to operate in two directions: one is to adapt production processes to the evolution of technology and markets, the other to act positively on the market, changing the needs of consumers to its advantage and making the most of the action of competitors.

The large firm fails to achieve the coincidence between the "economic" subject/entity, which gives the company the capital, and the "operating" one that takes the decisions; there is a fragmentation of the entrepreneurial power and, in part, this moves from the economic subject to other people who are tied to the company through an employment relationship. The organization is thus divided into three levels: the entrepreneurial, decision-making and, finally, the executive one. The economic subject that is the set of natural and legal persons in the interest of which the company was put in place occupies the entrepreneurial level. The decision making level is made by those whose power of decision is bounded by the scope assigned to them by the directives of the economic subject. Since the interests of those who constitute the economic subject dominate the choice of 
subjects, that have to direct and control the enterprise, we say that these interests govern the company. The executive level is made up of those who have to translate into action the decisions of the other two levels.

The functions to be performed by those involved in business activity can be divided into decision-making and execution-only, leading to the distinction between the centres of decision and execution centres.

With the formation of centres of decision making the entrepreneurial function is no longer exercised only by the economic entity, but also from such centres. Under certain conditions, which depend on the size or public property or private enterprise, professional managers, who possess the necessary skills, exercise the power of address management. This involves the status of "decision-making operating” subject for managers, who exercise part of the functions that refer to the economic subject. The characteristics of the last one have an influence on the management process, more or less evident depending on the size of the company. This influence is direct if there is coincidence between the economic subject and the decision-making operating one, otherwise it is indirect and depends on the degree of control that can be exercised by the former on the latter.

The size of the enterprise is the variable that is significantly correlated to the degree of fragmentation of the entrepreneurial power. The entrepreneurial and management power can be exercised by a single entity only in smaller firms, thus, when the company enlarges, the number of the subjects, to which is delegated the exercise of entrepreneurial activity, increases. Therefore there is a progressive fragmentation of power and a delegation process by which management spreads activities between the organs that form the organizational structure [6]. The components of the organization, on the other hand, must act as a unit to achieve the same purpose. Where it does not occurs the consonance of the objectives and there is a conflict, there can be no entrepreneurship and the enterprise cannot arise independently and last for long.

\section{The Role of Management in the Fragmentation of Entrepreneurial Function and the Agency Problem}

When various centres of decision-making carry out the entrepreneurial function we have a managerial organization of the firm. Business decisions are developed and implemented by people who, having a working knowledge of business and management techniques, may direct and coordinate the use of human resources, tangible and intangible assets available to the company-or to the part of the company they are responsible for-with rationality, thus trying to maximize the efficiency and the effective- ness in the implementation of business decisions to ensure the achievement of results consistent with corporate goals and stakeholder expectations. This situation creates an asymmetry of information between those who provided the venture capital (economic subject) and management (decision-making operating subject) that has the mandate to administer the capital, manages the processes of economic transformation and risk control, and usually knows the business better than the economic subject. In the case of managerial firm is therefore appropriate that in the company, whether publicly or privately owned, operates an internal control, that is a system of incentives that can keep control of the operating entity [7,8], aligning the motivations of centres of decision and the motivations of the economic subject, so that the efficiency of management and the profitability of the invested capital are pursued.

The agency theory $[9,10]$ effectively described the relation between the economic entity and the operating decision one-in case of separation of the two-and the problem of the control of the former on the latter and, today, it continues to offer effective key to understanding the issues related to corporate governance [11-13]. This theory defines the nature of the business based on contractual relationships that form between principal and agents. The principal contractually delegates one or more persons, agents, to accomplish a task that brings benefits, but he cannot personally do so equally efficiently. The power of the agents actually extends beyond the limits set by the contract, so the relationship is characterized by discretion. There is an information asymmetry because the agent's behaviour cannot be fully known by the principal and there is an imbalance in the distribution of results, as the principal bears the risk of the business and he perceives a residual remuneration. When the principal interest and the agent one and, as a result, the motivations do not match the inability of the principal to monitor the agent gets the latter to behave opportunistically, creating inefficiencies in the organization and, in particular, in the productive system of the firm. According to agency theory and the one of property rights [14,15] Jensen and Meckling [10] define economic legal entity the one who, having the ownership of the assets employed, is entitled to make decisions on the use of them. If the company operates in a competitive market, characterized by uncertain results, the economic entity on the one hand is risk bearer, on the other assumes the role of residual claimant. He has the right duty to retain the result residual remaining after having fulfilled all the obligations of the business management; the residual claim has the function to optimise the incentives of the owner to conduct monitoring [15] so the economic entity 
is the one who is suitable to perform the control of the other factors of production.

The problem of control of management is particularly evident in a public company where the ownership structure is characterized by a large number of shareholders, and the one who has control is the owner of a limited capital—or he is not a owner of capital—and there is the possibility that others purchase on the market dispersed shares, taking over the control. There is a separation of property rights in two parts: the power to manage the means of production and the right to enjoy the results of productive transformation. The separation between the operating entity and the economic subject, as we defined it, creates a situation where those who control does not have the residual results and they have no incentive to maintain an efficient behaviour. So with the disappearance of the unitary concept of ownership and the fragmentation of entrepreneurial function the figure of the manager assumes greater importance and there is the risk that it pursues objectives other than maximizing the value of the company and the shareholders' value. In the case of a public company, especially when the management through proxies and allies are able to control the bodies representative of shareholders, the wide dispersion of shareholders may not bring out the person who has the function of protecting the interests of shareholders. If the company, the type of activity or due to cash flows, is in the condition of not having to go to the market to obtain monetary resources increase the likelihood that management does not pursue the interests of shareholders so far as to deprive them of rights to remuneration and reimbursement of capital. In this situation, in fact, the operating entity — not being bound by market monitoring on the distribution of dividends and earnings produced-could expand enormously the part of value added destined to their remuneration or to other inputs.

\section{Corporate Control and Risk Management}

All firms, whatever their specific fields of operations, face a wide variety of risks, either external or internal. On the base of their peculiarities (sector, size, international activities, complexity, shareholders) they should develop an adequate risk culture and arrangements to manage them effectively. Some companies may face risks that significantly affect society as a whole: risks related to climate change, to the environment (e.g. the numerous dramatic oil spills or the Fukushima meltdowns), health, safety, human rights, etc. Some other operate critical infrastructure, the disruption or destructtion of which could have major cross-border impacts. Financial firms are so interconnected with the major players in every financial market around the world that problems with a single name (e.g. AIG) could create dramatic spillover effects transforming almost immediately what would seem a specific risk in a very systematic turmoil.

\subsection{Risk Management and Corporate Governance}

The risks that the company is facing in carrying out its activities, whether financial, pure, operational or business can be managed using a variety of strategies, techniques and tools. In order, however, that the risk management choices conform to the overall company strategy, it is imperative that management, stakeholders and the market have the tools to verify the adequacy of the choices made. The issue is very complex because of the multiplicity of subjects involved or interested in the management of the company: board of directors, managers, stakeholders and more generally, markets, and regulatory bodies. The control and risk management choices are subject to public scrutiny with the intent to protect all subjects who have dealings with the company, but they are equally important within the company, given the top management need for a clear and up to date check of the situation. In all cases we are faced with complex agency problems that are clearly endemic in corporations and widely present in contexts in which corporate ownership and control are separated, but also where there is a close connection between management and ownership. It is therefore not by chance that disastrous events that have severely affected businesses, shareholders and creditors in the last decades sometimes associated with risk management choices and sometimes derived from other choices have occurred in countries with different corporate governance systems as United States, Japan, Germany or Italy and resulted in the disruption or serious difficulties for firms like Barings, Enron, Metallgesellshaft, Parmalat, Worldcom, Lehman Brothers, AIG.

The economic crisis that has affected the world economy, the instability of financial markets, the complexity of business processes and the continuous evolution of regulations require successful companies to possess a renewed ability to protect and maximize the sources of value, both tangible and intangible, that characterize their business models.

The resolution of agency problems is approached differently depending on the corporate governance system in place. The governance models adopted in different countries is profoundly different from the formal point of view, but the ends they seek to achieve are similar. The system failures that the cases mentioned above testify, cannot be interpreted as evidence of the superiority or inferiority of one model of governance over another and, 
strictly speaking, does not by itself indicate either the inadequacy of the system of rules respect to the objecttives of governance, they are quite generally borderline cases in which the existing rules have been distorted or twisted, or wrongly applied to achieve goals that do not fit with the best interests of stakeholders, business and society. We can introduce special rules, enforce the existing ones or change the governance model to try to prevent the occurrence of such events, but we believe that the main way to limit these casualties is to monitor that the existing rules are applied in an effective and substantial way not formally. Of course we should find hardly surprising the occurrence of a small number of physiological events in which companies go bankrupt for these problems, the model of governance, every model, works well if we make sure that this number remains physiological. Two key pillars to approach and solve this issue are necessarily based on internal and external controls, i.e. board implementation and supervision of a consistent control function and auditing, but the most important external control system is given by public regulatory authorities.

\subsection{Internal and External Control Systems}

It is crucial that the board ensures a proper oversight of the risk management processes. To be effective and consistent any risk policy needs to be clearly stated by the board of directors for the whole organization. It is generally recognized that the board of directors bears primary responsibility for defining the risk profile of a given organization according to the strategy followed and monitoring it adequately to ensure it works effectively. Some aspects may differ due to the variety of legal frameworks in place. In Italy for instance the corporate law reform introduced the monistic model, based on the Anglo-Saxon governance system, and the dualistic model, based on the German corporate system, alongside the traditional model based on administrative controls by the "collegio sindacale" and accounting controls exercised by an external independent subject. In all cases, it is indispensable to define clearly the roles and responsibilities of all parties involved in the risk management process: the board, the executive management and all operational staff working in the risk function. The job descriptions must be known internally and externally. We have experimented in recent years the diffusion of codes of self-

\footnotetext{
${ }^{1}$ With accountants the adagio says: "It takes the FASB four years to come up with a rule and the finance guys about four hours to find a way around it", we stress that the best solution to prevent problems to arise or spread is based on a renewed code of ethical behavior by individuals and firms and a commitment to comply with the substance of the rules more than with a never ending pursuit between rules and dubious conducts.
}

regulation, in Italy the "Preda Code", issued in 1999 and reviewed several times from then, which defines the governance system for listed companies and their subsidiaries. The Codes of Conduct and the sequel of recommendations issued by several international bodies refer to the same fundamental principles of corporate governance, independent from specific country characteristics and their evolution. Generally speaking all codes give attention to such themes as:

1) Board structure and responsibility

2) Board and top management remuneration

3) Shareholder's rights

4) Disclosure and transparency

5) Internal control systems and risk management

The issues settled in the codes of self-regulation are part of the ongoing debate about the reform of the corporate governance system which produced in the last decade the "Sarbanes-Oxley" (2002) in USA and the "Loi de Sécurité Financière" (2003) in France with the aim to strengthen the corporate governance and control system of the corporations introducing and expanding the power of regulatory bodies, increasing the independence of the internal control system, and limiting the conflict of interest between board/management and shareholders, or between analysts, auditors and consultants and shareholders/markets on the other side.

The increasing diffusion of codes of ethics, codes of behavior, etc. reinforces the inclination toward the achievement of standards of high reputation. Codes should express the ethical responsibility of the organization towards stakeholders and promote an internal system of shared values. But this complex set of rules, that at different levels impose various layers of restrictions on what the firms can or cannot do, needs to be necessarily connected to the ethical behavior of individuals both at the personal and professional level ${ }^{1}$. Otherwise the imposition of new set of rules, one more stringent than the former, cannot per se produce the desired results on people's behavior, as acutely expressed by Jennings [16] that says: "We suffer from a dependency on laws and regulations and from myopia when it comes to ethics. Until the law tells us a practice is wrong, we continue what we're doing, taking comfort in dotting the i's and crossing the t's to comply with detailed reforms. In focusing on the details of the reforms, we miss the big picture of industry practices that clearly cross ethical lines but continue because current regulations have not yet found them to be legally problematic".

\subsection{Shareholder Engagement, Risk Management and Corporate Governance}

The EU Green Paper on corporate governance in finan- 
cial institutions, published in June 2010 found that a lack of appropriate shareholder interest in holding financial institutions' management accountable contributed to poor management accountability and may have facilitated excessive risk taking in financial institutions. The results in the Green Paper suggest that, in many cases, shareholders deemed the expected profits from taking these risks worthwhile and so implicitly supported excessive risk taking, especially though high leverage. The main reason is that shareholders would fully benefit from the upside of such a strategy, while they participate in losses only until the value of shareholder equity reaches zero, after which further losses would be borne by the creditors thanks to the limited liability rule. The recent trend of growing importance of alternative investment institutions such as private equity, hedge funds, sovereign wealth funds, infrastructure funds, have implications for the management and governance of every firm.

The behavior of shareholders in financial institutions, in relation to excessive risk taking, is not a peculiar or isolated case related to the complexity and difficulty to understand the operations implemented by management. The evidence gathered during the preparation of the Green Paper "The EU corporate governance framework" (2011) suggests that the findings of the 2010 Green Paper regarding the lack of shareholder engagement and the reasons for this are also relevant to shareholder behavior in listed companies with dispersed ownership ("public companies"). On the other side in companies with a dominant or controlling shareholder, which still represent the predominant governance model in European countries, it seems that the major challenge is to ensure that the interests of minority shareholders are adequately protected against the spoiling actions of controlling shareholders (e.g. Parmalat case) and/or the management. Controlling shareholders and the management can extract the control benefits damaging minority shareholders' interests in many ways. The main way is through 'related party' transactions. EU Countries actually have rules about accounting and disclosure of related party transacttions but these rules are in our opinion, and in the opinion of a large stake of the investment community, by far insufficient to prevent detrimental actions against minority shareholders and to give timely and accurate disclosure of necessary information about related party transactions. One possibility to prevent this sort of conflict of interest is that, above a certain threshold, the board should appoint an independent expert or a panel of independent administrators to provide an impartial opinion on the terms and conditions of related party transactions to the minority shareholders and that significant related party transactions would need approval by the general meeting. The publicity associated with general meetings might dissuade controlling shareholders from some transactions and give minority shareholders the chance to oppose the resolution approving the transaction. In these cases we can also introduce rules with the aim to preclude to the controlling shareholders the right to vote the resolution. Anyway it is unlikely that such changes will modify dramatically the risk appetite of shareholders, to limit excessive risk taking by financial firms we need a radical change in the required capital ratios or some other form of control.

The regulators, aware of the byproducts of the globalization process for the financial sector attempted from Basel I to regulate the activities that might potentially generate such risks subordinating them to specific sector legislation and the monitoring of regulatory bodies. Unfortunately the same process of regulation created in the last 25 years several undesired effects on the evolution and risk management of the banking sector leading from one side to substantial regulatory arbitrage and from the other to excessive risk creation and distribution that caused the last financial crisis. Given the outcome of the recent turmoil becomes crucial for industrial and financial firms but also for regulatory bodies to support any action that can further strengthen the system of corporate governance by introducing a "proactive" risk management model. This model allows, in a systematic and structured way, the identification, analysis and evaluation of the risk areas that could jeopardize the achievement of strategic goals and, at the same time, provides the board of directors and top management the tools necessary for making decisions aimed at anticipating and managing the effects of these risks.

Some problems, unfortunately, as the financial crisis of 2007-8 makes clear, are the result of the existence of several supervisory bodies, the confusion of the roles and rules governing the respective areas of intervention, the limited exchange of data, information and support between them. And this in not all, because a key factor in the last crisis and perhaps in the next one, is given by the difference in rules applied to different actors (commercial banks, investment banks, insurance co., hedge funds, sovereign wealth funds, infrastructure funds, private equity), and the existence of gray areas within the broad definition of "domestic financial sector" and in the international financial markets where nobody is in charge, we should maybe contemplate the hypothesis to restrict certain kinds of transactions only to subjects with similar regulatory status to prevent any sort of regulatory arbitrage.

\section{Conclusions}

This work interprets corporate governance as an outcome of the fragmentation of the entrepreneurial function. This 
phenomenon takes place when the firm dimension increases and the entrepreneurial function shifts from the owner of equity to the organizational structure. According to the agency theory and the property rights theory this paper frames the problem of management control and risk management as a result of an agency conflict caused by separation of decision and risk-bearing functions and by the conflict between controlling and minority shareholders. An effective corporate governance system is one that helps solve these conflicts limiting the business failures dues to excessive risk taking and other causes of mismanagement to physiological levels. A key component of every sound model of governance is the control system in both the internal and external facets. We stresses the need of effective internal (systems of incentives) and external controls (market and public regulatory authorities), and an effective code of ethics for individuals and firms alike. The engagement of shareholders poses issues related to the risk taking choices and the control of related party transactions, that can be addressed in several ways. Last but not least, the existence of several supervisory bodies, the confusion of the roles and rules governing the respective areas of intervention, the limited exchange of data, information and support between them, creates firms with different regulatory status engaged in activities of regulatory arbitrage that should be addressed.

\section{REFERENCES}

[1] J. S. L. Plummer, J. M. Hany and J. Godesiabois, "An Essay on the Origins of Entrepreneurial Opportunity," Small Business Economics, Vol. 28, No. 4, 2007, pp. 363379. doi:10.1007/s11187-006-9036-8

[2] T. Eckhardt and S. A. Shane, "Opportunities and Entrepreneurship,” Journal of Management, Vol. 29, No. 3, 2003, pp. 333-349. doi:10.1016/S0149-2063(02)00225-8

[3] S. D. Sarasvathy, "Entrepreneurship as a Science of the Artificial,” Journal of Economic Psychology, Vol. 24, No. 2, 2003, pp. 203-220. doi:10.1016/S0167-4870(02)00203-9

[4] S. A. Shane and S. Venkataraman, "Entrepreneurship as a Field of Research: A Response to Zahra and Dess, Singh, and Erikson," The Academy of Management Review, Vol. 26, No. 1, 2001, pp. 13-16.

\section{doi:10.5465/AMR.2001.27879269}

[5] S. A. Shane and S. Venkataraman, "The Promise of Entrepreneurship as a Field of Research,” Academy of Management Review, Vol. 25, 2000, pp. 217-226.

[6] A. A. Berle and G. C. Means, "The Modern Corporation \& Private Property,” Transaction Publishers, New Brunswick, 1991.

[7] D. Czarnitzk and K. Kraft, "Management Control and Innovative Activity," Review of Industrial Organization, Vol. 24, No. 1, 2004, pp. 1-24. doi:10.1023/B:REIO.0000031361.27597.7c

[8] G. Chen, M. Firth, D. N. Gau and O. M. Rui, "Ownership Structure, Corporate Governance and Fraud: Evidence from China,” Journal of Corporate Finance, Vol. 12, No. 3, 2006, pp. 424-448. doi:10.1016/j.jcorpfin.2005.09.002

[9] S. A. Ross, "The Economic Theory of Agency: The Principal's Problems,” American Economic Review, Vol. 63, 1973, pp. 134-139.

[10] M. C. Jensen and W. H. Meckling, "Theory of the Firm: Mangerial Behavior, Agency Cost and Capital Structure," Journal of Financial Economics, Vol. 3, No. 4, 1976, pp. 305-360. doi:10.1016/0304-405X(76)90026-X

[11] D. B. Audretsch, E. E. Lehman and L. A. Plummer, "Agency and Governance in Strategic Entrepreneurship," Entrepreneurship Theory and Practice, Vol. 33, No. 1, 2009, pp. 149-166. doi:10.1111/j.1540-6520.2008.00284.x

[12] M. Singh and W. N. Davidson, "Agency Costs, Ownership Structure and Corporate Governance Mechanisms," Journal of Banking \& Finance, Vol. 27, No. 5, 2003, pp. 793-816. doi:10.1016/S0378-4266(01)00260-6

[13] S. Reichelstein, "Providing Managerial Incentives: Cash Flows versus Accrual Accounting," Journal of Accounting Research, Vol. 38, No. 2, 2000, pp. 243-269. doi:10.2307/2672933

[14] R. Coase, "The Problem of Social Cost," Journal of Law and Economics, Vol. 3, No. 1, 1960, pp. 1-44. doi:10.1086/466560

[15] A. Alchian and H. Demsetz, "Production, Information Cost, and Economic Organization,” American Economic Review, Vol. 62, No. 5, 1972, pp. 777-795.

[16] M. M. Jennings, "Ethics and Investment Management: True Reform,” Financial Analysts Journal, Vol. 61, No. 3, 2005, pp. 45-58. doi:10.2469/faj.v61.n3.2727 